\title{
Poliomyelitis, a disease eradicated in America. An Ibero-American philatelic approach
}

\author{
In memory of Ibero-American pediatrician \\ and public health medical officer \\ Patricio Hevia Rivas, M.D. (1935-2020)
}

A way of accessing the graphic testimony of the historical, cultural or scientific events of a specific country or geographic region is philately. This is where infectious diseases and a laborious attempt to control and eradicate them, as many other achievements in health policy, find a privileged position through the different thematic disciplines of this hobby. ${ }^{1}$

Knowledge about and collection of postage stamps have now become an increasingly rare and neglected pastime. In addition, there is sometimes a marked historical ignorance ("a disease from the past"), a lack of appreciation of effective control measures (vaccines) ${ }^{2}$ or an obvious absence of empathy from today's population in a similar epidemiological context, who have forgotten the horrific effects of polio, like those of many other infectious diseases, on the everyday life of the society of that time.

More than 25 years have elapsed since the eradication of polio in America was certified, an event that, together with the 65 year-anniversary since the initiation of immunizations in Argentina and 60 year-anniversary in Chile, ${ }^{2,3}$ are important dates to remember and celebrate, this time, through the visual testimony offered by philately, a source of history.

\section{About poliomyelitis and stamps}

The world's first postage stamp, "Penny Black," was issued on May $6^{\text {th }}, 1840$; it had a face value of 1 penny and featured the profile of a young Queen Victoria of Great Britain. It was invented by Sir Rowland Hill. In Chile, the first stamp, which featured Christopher Columbus, was issued in 1853 and had a face value of 5 and 10 cents. In Argentina, the first stamp was issued in the province of Corrientes in 1856 and showed Ceres, the Roman goddess of agriculture, grain crops, and fertility, in honor of the country, which was at the time considered the granary of the world.
Almost certainly, polio is an ancient disease in the history of humankind, as evidenced in the bas-reliefs of the Saqqara pyramid and Egyptian funerary steles. This virus has probably been with us since men first gathered in large groups or societies.

In 1890, Swedish pediatrician Karl Oskar Medin (1847-1927) described, in great detail, the epidemic of infantile paralysis in the Scandinavian Peninsula and pointed out that, in addition to myelitis, there were several, previously unknown, clinical presentations of neurological complications (bulbar, encephalitic, polyneuritic, and ataxic). ${ }^{3,4}$ In our continent, polio first occurred in epidemic outbreaks since the mid- $20^{\text {th }}$ century and left a trail of residual morbidity and mortality in part of the pediatric population. ${ }^{3,5}$

\section{Polio vaccine research and development}

In 1909, Landsteiner, Popper, Flexner, and Lewis managed to reproduce polio at the level of animal experimentation. ${ }^{3}$ But it would not be until January 1938, with the establishment, in the United States, of the National Foundation for Infantile Paralysis, promoted by president Franklin D. Roosevelt, that the fight against polio would reach its peak of magnificence. ${ }^{6}$ A decade later, the scientific community started devoting its efforts to finding an effective vaccine. In 1949, three American virologists working at the Boston Children's Medical Center, Enders, Weller, and Robbins, brought about a true revolution in virology by multiplying the three polio viruses in vitro in non-nervous cells cultures, which paved the way towards a vaccine. ${ }^{7}$

However, virologist Jonas E. Salk (1914-1995), from the University of Pittsburgh, first developed it successfully. ${ }^{3}$ Salk obtained a highly effective inactivated vaccine so, in 1954, clinical trials started with positive results in 1.8 million children and an authorization for its use was granted the following year. At first, the vaccine showed safety concerns resulting from the need to have it available rapidly and the limited controls before its release, which were finally resolved. However, this affected Salk, who decided to travel to Europe to consolidate the principles of vaccinology and 
thus produce a new vaccine, which was registered more than a decade later. ${ }^{3}$

In spite of Salk's inactivated vaccine success, he went on to develop a live, attenuated (oral) vaccine. Then, in 1953, Polish-American investigator Albert Bruce Sabin, M.D. (1906-1995), from Cincinnati, obtained the first poliovirus attenuated strain and patented, a decade later, the trivalent oral polio vaccine. The following year, the Committee on Infectious Diseases of the American Academy of Pediatrics recommended a single dose of the oral vaccine, which prevailed worldwide given its evident advantages in terms of cost, delivery, and mechanism of action. In South America, this was the systematic and universal polio vaccine. ${ }^{5}$

Ibero-American postage stamps depicting symptoms of paralysis resulting from poliomyelitis, immunization campaigns, and the celebration of its eradication.

So, what is the relation between philately and poliomyelitis?

The impact of polio on the community becomes evident in the fact that it was featured in several Ibero-American postage stamps, which depicted symptoms, immunization campaigns, and its eradication, among other things (Figure 1). In Chile, it is worth noting a postage stamp from 1944 (Figure 1) corresponding to a non-profit association whose members were volunteers devoted to children protection, especially dedicated to health prevention and helping children infected with polio. As seen, the design shows a child with the lower half of the body wrapped in cloth, similar to the images of $I l$

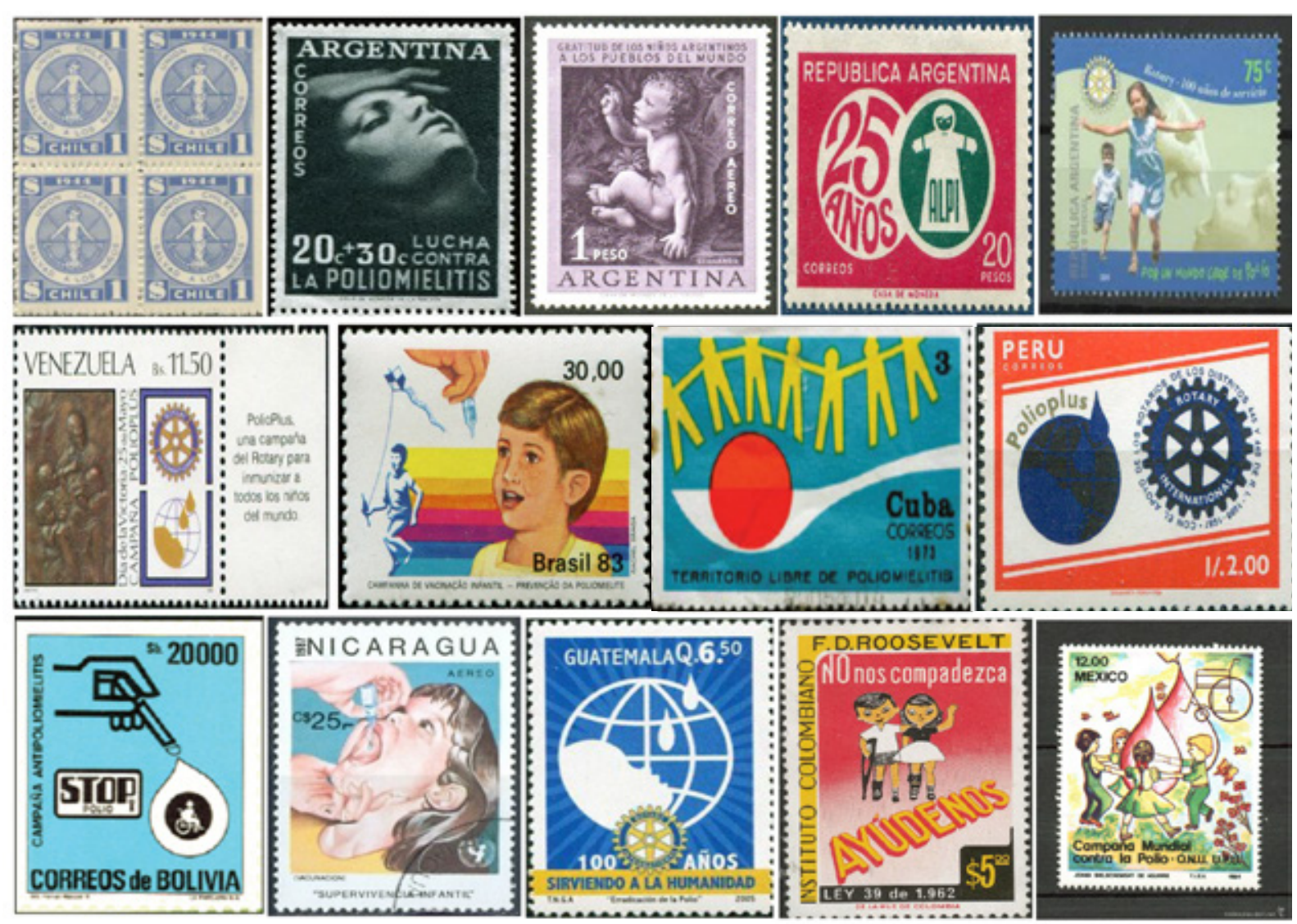

Postage stamps from Latin America showing symptoms of paralysis caused by poliomyelitis, vaccination campaigns and commemoration of its eradication 
Bambino de L'Ospedale degli Innocenti, in Florence, Italy. The Chilean stamp was in blue and red.

In relation to Argentine stamps, it is worth noting the representation of the head of a female adolescent attacked by polio and a hand stroking her forehead (1956); another one in appreciation of international help to fight polio; one to commemorate the $25^{\text {th }}$ anniversary of the Association for the Fight against Infantile Paralysis (Asociación para la Lucha contra la Parálisis Infantil, ALPI), which was founded in 1943 by the initiative of Marcelo J. Fitte, M.D., and helped with a large, national immunization campaign. Finally, there is a commemorative stamp from 2005 in celebration of the $100^{\text {th }}$ anniversary of the Rotary International showing children running around and the text "For a world free of polio" (Figure 1).

As observed, Ibero-American philately did not remain detached from the historical context of the times. It may even be pointed out that, sometimes, the historical context inspired the issuance of certain stamps. This way, such brief approach to pediatric philately has allowed us to bear in mind that postage stamps have been used for health campaigns or other medical themes. Subjects like health education, child growth and development supervision, breastfeeding promotion, immunization, and recognition of different milestones achieved in Ibero-American pediatrics are worth noting. Stamps may be seen as an educational theme and a source of investigation because they were a relevant tool for pediatric health promotion and community education, especially in developing countries. ${ }^{1}$

The last polio case in America was detected in 1991, in a child called Luis Fermín from the Department of Junín, Peru. In Chile, no cases have been reported since 1975 and, in Argentina, since 1984. This way, polio was the second vaccine-preventable disease to be eradicated in the Americas once the Global Commission for the Certification of the Eradication of Poliomyelitis declared wild poliovirus transmission interrupted (first region in the world) in $1994 .^{3}$

Nowadays, polio is still an endemic disease in Nigeria, Pakistan, and Afghanistan, and emerges occasionally in countries at war. ${ }^{3}$ The Region of the Americas must maintain the current immunization levels until the entire world has been certified as free of polio. A pending but enthusiastic mission.

\section{Alejandro Donoso F. ${ }^{a}$ and Daniela Arriagada $S .{ }^{a}$ \\ ${ }^{a}$ M.D., Unit of Pediatric Critical Patients, Hospital Dra. Eloísa Díaz I., La Florida, \\ Santiago, Chile. \\ E-mail address of Alejandro Donoso F., M.D.: adonosofuentes@gmail.com.}

http:/ / dx.doi.org/10.5546/ aap.2020.eng.375

To cite: Donoso F. A., Arriagada S. D. Poliomyelitis, a disease eradicated in America. An Ibero-American philatelic approach. Arch Argent Pediatr 2020;118(6):375-377.

\section{REFERENCES}

1. Senanayake MP. Paediatric philately. Arch Dis Child.1997;76(3):287-8.

2. Hevia Rivas P. Apoyo de un sistema pediátrico a los planes de vacunación. Sal Púb Mex. 1979; XX(4):409-19.

3. Dibarboure H. Reflexiones sobre la historia de las vacunas contra la poliomielitis Rev Chil Infectol. 2018; 35(4):436-44.

4. Laval RE. Anotaciones para la historia de la poliomielits en Chile. Rev Chil Infect. 2007; 24(3):247-50.

5. Sabin A. Vacuna oral contra la poliomielitis. Realizaciones y problemas en su uso a escala mundial. Arch Argent Pediatr. 1978; 79(4):180-5.

6. Katz SL. From culture to vaccine-Salk and Sabin. N Engl J Med. 2004; 351(15):1485-7.

7. Chastel C. Sixty years ago, cell cultures finally permitted the poliomyelitis virus to multiply easily. Hist Sci Med. 2009; 43(4):345-55. 